\title{
Prevalence of Abnormal Body Posture Among Chinese Children and Adolescents: A Large Population-Based Cross-Sectional Study
}

\author{
Lei Yang ${ }^{1}$, Xinhai Lu ${ }^{1,2,3}$, Bin Yan ${ }^{1,2,3 \#}$ and Yeen Huang ${ }^{1,2,3 \# *}$ \\ ${ }^{1}$ The First Affiliated Hospital of Shenzhen University, Shenzhen, China \\ ${ }^{2}$ The Shenzhen Second People's Hospital, Shenzhen, China
}

${ }^{3}$ Shenzhen Youth Spine Health Center, Shenzhen, China

\#These authors contributed equally to this work

*Corresponding author: Yeen Huang, the First Affiliated Hospital of Shenzhen University, the Shenzhen Second People's Hospital, Shenzhen Youth Spine, Health Center, China

\section{ARTICLE INFO}

Received: 慧 January 20, 2020

Published: 幽 January 28, 2020

Citation: Lei Yang, Xinhai Lu, Bin Yan, Yeen Huang. Prevalence of Abnormal Body Posture Among Chinese Children and Adolescents: A Large Population-Based Cross-Sectional Study. Biomed J Sci \& Tech Res 25(1)-2020. BJSTR. MS.ID.004140.

Keywords: Abnormal Body Posture; Prevalence; Children; Adolescent; School Screening Program

Abbreviations: AIS: Adolescent Idiopathic Scoliosis; GDP: Gross Domestic Product; FBT: Forward Bending Test; ATR: Angle of Trunk Rotation

\begin{abstract}
Objective: Evidence showed that the poor body posture in adulthood is often formed from the childhood, and individuals with severe abnormal body posture may associated with the progress to scoliosis. However, there is still a lack of epidemiological evidence in the prevalence of adolescent abnormal body posture compared to scoliosis. To estimate the prevalence of abnormal body posture among children and adolescents, and to describe the epidemiological findings according to the demographic characteristics.
\end{abstract}

Study Design: This is a population-based, cross-sectional study of school screening program in south China. We sample a large representative dataset comprising data collected from 1st to 12th graders using a multistage, stratified-cluster, random-sampling method. Our sample consisted of 158,584 children and adolescents who were screened by visual inspection of clinical signs, the forward-bending test, and the measurement of angle of trunk rotation (ATR). The demographic characteristic and results of screening tests were collected and analyzed.

Results: A total of 158,584 school students were screened, with a boys-to-girls ratio of 1.2:1. The overall prevalence of abnormal body posture in Chinese children and adolescents was 65.3\% (95\% CI: 65.0\%-65.5\%), around 3.7\% (95\% CI: 3.6\%-3.8\%) of children and adolescents were referred for radiography. According to gender and age, girls had a higher prevalence of abnormal body posture than boys $(76.0 \%$ vs. $56.6 \%$, $\chi 2=6519.15, \mathrm{P}<0.001)$, students aged $10-15$ and $>15$ years old had a higher prevalence of abnormal body posture than students $<10$ years old $(64.8 \%$ and $71.1 \%$ vs. $41.3 \%$, $\chi 2=681.18, \mathrm{P}<0.001)$.

Conclusion: Our findings showed that Chinese children and adolescents have a significantly higher prevalence of abnormal body posture, girls and older students may be an especially high-risk group. Prevention and intervention programs targeting for school students should be established to improve their physical health.

\section{Introduction}

Abnormal body posture refers to an abnormal body state in which the body cannot maintain a stable state and the normal function of tissues and organs in an upright state [1]. Previous studies have shown that the poor body posture in adulthood is often formed from the childhood [2]. Children and adolescents with severe abnormal body posture may associated with the progress to Adolescent Idiopathic Scoliosis (AIS) [3,4]. Understanding the current prevalence of abnormal body posture of children and adolescents will help to identify high-risk population and formulate targeted interventions. Previous studies showed that $34 \%-50 \%$ of 
children and adolescents have different degrees of abnormal body posture [5,6] less than a fifth of children and adolescents have a normal body posture [7] most of the children have certain abnormal posture problems (e.g. shoulder asymmetry, kyphosis, or scapula tilt). Furthermore, some researchers suggested that compared with children of the same age who have not received school education, the students who have received school education have more serious body posture problems $[8,9]$.

To the best of our knowledge, previous evidence mainly come from the western or developed countries. In China, only one school screening program conducted in Beijing showed that nearly $80 \%$ of children and adolescents were reported to have at least one sign of abnormal body postures [10]. However, there is still a lack of largescale epidemiological evidence in the prevalence of adolescent abnormal body posture. Therefore, we conducted this large-scale cross-sectional study in south China to estimate the prevalence of abnormal body posture among children and adolescents, to describe the epidemiological findings according to the demographic characteristics, to provide data support for finding high-risk population and targeted interventions.

\section{Materials and Methods}

\section{Study Design and Participants}

This is a school-based cross-sectional study in children and adolescent students from the Shenzhen city in south China. All students were selected by a 3-stage, stratified-cluster, randomsampling method. In stage 1, we divided Shenzhen city into three economic stratifications (high-level, middle-level, and low-level) by per capita GDP (Gross Domestic Product), and then selected two districts from each stratification by simple randomization using random number generator. In stage 2, schools in each district were divided into three categories: primary schools (i.e., grades 1-6), junior high schools (i.e., grades 7-9), and senior high schools (i.e., grades 10-12). Based on the proportions of these three types of schools, six primary schools, six junior high schools, and three senior high schools were randomly selected from each representative district. In stage 3, all classes from each grade within the selected schools were included in our study, and all available students in the selected classes were invited to voluntarily participate in the present study. In total, 159,120 students were invited to participated in our scoliosis screening, 158,584 students were completed and qualified for our study.

\section{Ethical Statement}

This study was conducted in accordance with the Declaration of Helsinki and was approved by the Shenzhen Second People's Hospital Institutional Review Board (ethic code: SZ20130816). Written or oral informed consent was obtained from the parent or legal guardian of each participating student under 18 years old or from each participating student who at least 18 years old.

\section{Data Collection}

To protect the privacy of the students, all students in the selected classes were screened for scoliosis in a closed room or tent and administered by research assistants without the presence of teachers or other school personnel (to avoid potential information bias). All data were collected from September to November 2019.

\section{School Screening Program}

The school screening program for AIS in Shenzhen was started in 2013 as part of the national public health project, and conducted and administered by the Shenzhen Youth Spine Health Center (SYSHC) of the Shenzhen Second People's Hospital using a national scoliosis screening standardized protocol (GB/T 16133-2014) [11]. Students in primary schools, junior high schools, and high schools were invited to participate in the screening program voluntarily. School screening was performed by an experienced team of trained rehabilitation therapists from SYSHC using the Adams Forward Bending Test (FBT), visual inspection, and measurement of the Angle of Trunk Rotation (ATR) using the scoliometer [12].

\section{Abnormal Body Posture}

Abnormal body posture was assessed by visual inspection, FBT, and ATR $[13,14]$. The standard visual inspection was performed in the upright position. The examiner checked for spine alignment, shoulder asymmetry (high and low shoulder), scapula prominence (scapula tilt), hip and pelvic obliquity (pelvic tilt), back symmetry (flat back, kyphosis), lumbar curvature (lumbar concave, lumbar lordosis, and lumbar kyphosis), distance of the hands from the flanks, and length of the lower limbs [15]. The FBT was performed with the student's feet placed together, knees straight, while bending at the hips to nearly 90 degrees with the arms freely hanging forward, palms together. Any significant clinical sign was recorded. The ATR was used to decide the frequency of assessments and when should the students be referred for radiography directly by measuring with a scoliometer, including angle of thoracic rotation, angle of lumbar rotation, and angle of thoracolumbar rotation [16]. Students with an ATR $>5^{\circ}$ or with 1 or more significant clinical signs were identified as abnormal body posture.

\section{Demographic Variables}

Demographic variables included gender (boy, girl), age, ethnic group, school category, and grade. Ethnic group was assessed based on the student's self-report about their ethnic group (Han or minorities) [17]. School category included primary school (grade 1-6), junior middle school (grade 7-9), and high school (grade 10-12).

\section{Statistical Analysis}

First, descriptive analyses were conducted to describe the demographic characteristics (e.g. gender and age) of children and adolescents in south China. Second, prevalence of abnormal body posture among total population was reported, and sample was 
further divided into different groups to calculate gender-, age, school-specific prevalence rates. Chi-square test $\left(\chi^{2}\right)$ was used to compare the differences between groups. Bias-corrected $95 \%$ confidence intervals (CI) were estimated using 1000 bootstrap samples. All data were analyzed using SPSS 22.0 (IBM Corp, Armonk, NY, USA), a two-tailed with a P-value of less than 0.05 was considered statistically significant.

\section{Results}

\section{Demographic Characteristics of Chinese Children and Adolescents}

The sample demographic information was shown in Table 1. A total of 158,584 Chinese children and adolescents were screened, $55.3 \%$ (87754) were boys, and $44.7 \%$ were girls, yielding a maleto-female ratio of 1.2:1, and the mean (SD) age of the students was $12.8 \pm 2.0$ years. Primary school, junior high school, and senior high school students account for $38.0 \%, 42.7 \%$, and $19.3 \%$ respectively.

Table 1: Demographic characteristics of Chinese children and adolescents $(\mathrm{N}=158,584)$.

\begin{tabular}{|c|c|}
\hline Variables & N (\%) \\
\hline \multicolumn{2}{|c|}{ Gender } \\
\hline Boy & 87754 (55.3) \\
\hline Girl & $70830(44.7)$ \\
\hline Age (Mean \pm SD) & $12.8 \pm 2.0$ \\
\hline \multicolumn{2}{|c|}{ Ethnic group } \\
\hline Han & $153886(97.0)$ \\
\hline Minority & $4662(3.0)$ \\
\hline \multicolumn{2}{|c|}{ School category } \\
\hline Primary school & $60131(38.0)$ \\
\hline Junior middle school & $67785(42.7)$ \\
\hline High school & 30668 (19.3) \\
\hline \multicolumn{2}{|c|}{ Grade } \\
\hline Grade 1 & $394(0.2)$ \\
\hline Grade 2 & $401(0.3)$ \\
\hline Grade 3 & $400(0.3)$ \\
\hline Grade 4 & $461(0.3)$ \\
\hline Grade 5 & 30107 (19.0) \\
\hline Grade 6 & 28368 (17.9) \\
\hline Grade 7 & $24352(15.4)$ \\
\hline Grade 8 & $24008(15.0)$ \\
\hline Grade 9 & $19425(12.2)$ \\
\hline Grade 10 & $15881(10.0)$ \\
\hline Grade 11 & $14200(9.0)$ \\
\hline Grade 12 & $587(0.4)$ \\
\hline
\end{tabular}

Abbreviations: N: Number; SD: Standard Deviation.

\section{Prevalence of Abnormal Body Posture of Chinese Children and Adolescents}

As shown in Table 2, the overall prevalence of abnormal body posture among Chinese children and adolescents was 65.3\% (95\%
CI: 65.0\%-65.5\%), around 3.7\% (95\% CI: 3.6\%-3.8\%) of children and adolescents were referred for radiography. The most serious sign of abnormal body posture was high and low shoulders (left shoulder height: 30.2\%, 95\% CI: 30.0\%-30.5\%; Right shoulder height: $24.5 \%, 95 \% \mathrm{CI}: 24.2 \%-24.7 \%$ ) and scapula tilt (tilt to the left: $25.2 \%$, 95\% CI: $25.0 \%-25.5 \%$; tilt to the right: $17.0 \%, 95 \% \mathrm{CI}$ : $16.8 \%-17.1 \%)$.

Table 2: Prevalence of abnormal body posture among Chinese children and adolescents.

\begin{tabular}{|c|c|c|}
\hline Variables & N (\%) & $95 \% \mathrm{CI}$ \\
\hline Total & $158584(100.0)$ & \\
\hline \multicolumn{3}{|c|}{ High and low shoulder } \\
\hline Normal & $71832(45.3)$ & $45.1 \%-45.6 \%$ \\
\hline Left shoulder height & $47935(30.2)$ & $30.0 \%-30.5 \%$ \\
\hline Right shoulder height & $38817(24.5)$ & $24.2 \%-24.7 \%$ \\
\hline \multicolumn{3}{|c|}{ Scapula tilt } \\
\hline Normal & $91695(57.8)$ & $57.6 \%-58.1 \%$ \\
\hline Tilt to the left & $40007(25.2)$ & $25.0 \%-25.5 \%$ \\
\hline Tilt to the right & $26882(17.0)$ & $16.8 \%-17.1 \%$ \\
\hline \multicolumn{3}{|c|}{ Pelvic tilt } \\
\hline Normal & $146165(92.2)$ & $92.0 \%-92.3 \%$ \\
\hline Tilt to the left & $6009(3.8)$ & $3.7 \%-3.9 \%$ \\
\hline Tilt to the right & $6410(4.0)$ & $3.9 \%-4.2 \%$ \\
\hline \multicolumn{3}{|c|}{ Flat back } \\
\hline Normal & 157507 (99.3) & $99.2 \%-99.4 \%$ \\
\hline Abnormal & $1077(0.7)$ & $0.6 \%-0.8 \%$ \\
\hline \multicolumn{3}{|c|}{ Kyphosis } \\
\hline Normal & $154264(97.3)$ & $97.2 \%-97.4 \%$ \\
\hline Abnormal & $4320(2.7)$ & $2.6 \%-2.8 \%$ \\
\hline \multicolumn{3}{|c|}{ Lumbar concave } \\
\hline Normal & $122166(77.0)$ & $76.8 \%-77.2 \%$ \\
\hline Left concave & $14754(9.3)$ & $9.2 \%-9.4 \%$ \\
\hline Right concave & 21664 (13.7) & $13.5 \%-13.8 \%$ \\
\hline \multicolumn{3}{|c|}{ Lumbar lordosis } \\
\hline Normal & $157834(99.5)$ & $99.4 \%-99.6 \%$ \\
\hline Abnormal & $750(0.5)$ & $0.4 \%-0.6 \%$ \\
\hline \multicolumn{3}{|c|}{ Lumbar kyphosis } \\
\hline Normal & 158264 (99.8) & $99.7 \%-99.9 \%$ \\
\hline Abnormal & $320(0.2)$ & $0.1 \%-0.3 \%$ \\
\hline \multicolumn{3}{|c|}{ Angle of thoracic rotation } \\
\hline Normal (ATR: 0-5) & $156239(98.5)$ & $98.4 \%-98.6 \%$ \\
\hline Rotate to the left $\left(\mathrm{ATR}>5^{\circ}\right)$ & $696(0.4)$ & $0.3 \%-0.5 \%$ \\
\hline Rotate to the right $\left(\mathrm{ATR}>5^{\circ}\right)$ & $1649(1.1)$ & $1.0 \%-1.2 \%$ \\
\hline \multicolumn{3}{|c|}{ Angle of lumbar rotation } \\
\hline Normal (ATR: $0-5^{\circ}$ ) & 155291 (97.9) & $97.8 \%-98.0 \%$ \\
\hline
\end{tabular}




\begin{tabular}{|c|c|c|}
\hline Rotate to the left $\left(\mathrm{ATR}>5^{\circ}\right)$ & $2470(1.6)$ & $1.5 \%-1.7 \%$ \\
\hline Rotate to the right $\left(\mathrm{ATR}>5^{\circ}\right)$ & $823(0.5)$ & $0.4 \%-0.6 \%$ \\
\hline \multicolumn{3}{|c|}{ Angle of thoracolumbar rotation } \\
\hline Normal (ATR: 0-5) & 157885 (99.6) & $99.5 \%-99.7 \%$ \\
\hline Rotate to the left $\left(\mathrm{ATR}>5^{\circ}\right)$ & $309(0.2)$ & $0.1 \%-0.3 \%$ \\
\hline Rotate to the right $\left(\mathrm{ATR}>5^{\circ}\right)$ & $309(0.2)$ & $0.1 \%-0.3 \%$ \\
\hline \multicolumn{3}{|c|}{ Abnormal body posture ${ }^{a}$} \\
\hline Normal & $55048(34.7)$ & $34.5 \%-35.0 \%$ \\
\hline Abnormal & $103536(65.3)$ & $65.0 \%-65.5 \%$ \\
\hline \multicolumn{3}{|c|}{ Referral for radiographyb } \\
\hline No & $152775(96.3)$ & $96.2 \%-96.4 \%$ \\
\hline Yes & 5809 (3.7) & $3.6 \%-3.8 \%$ \\
\hline
\end{tabular}

Abbreviations: N: Number; CI: Confidence Intervals; ATR, Angle of Trunk Rotation. a) Abnormal body posture was defined as participant who was screened out one or more to the following abnormal physical signs: high and low shoulder, scapula tilt, pelvic tilt, flat back, kyphosis, lumbar concave, lumbar lordosis, lumbar kyphosis, angle of thoracic rotation $>5^{\circ}$, angle of lumbar rotation $>5^{\circ}$, angle of thoracolumbar rotation $>5^{\circ}$.

b) Referral for radiography: an angle of trunk (thoracic, lumbar or thoracolumbar) rotation of $5^{\circ}$ was the recommended threshold for referral to radiography.

\section{Prevalence of Abnormal Body Posture of Chinese Children and Adolescents Stratified by Gender}

According to gender (as shown in Table 3), the prevalence of abnormal body posture was significantly higher in girls than that in boys $\left(76.0 \%\right.$ vs. $\left.56.6 \%, \chi^{2}=6519.15, \mathrm{P}<0.001\right)$, girls had a 1.34 times higher prevalence of abnormal body posture than boys. Girls had a higher prevalence of referral for radiography than boys $(5.2 \% \mathrm{vs}$. $\left.2.4 \%, \chi^{2}=822.31, \mathrm{P}<0.001\right)$. Besides pelvic tilt and kyphosis, the rest of the abnormal signs were higher for girls than boys.

Table 3: Prevalence of abnormal body posture stratified by gender $(\mathrm{N}=158,584)$.

\begin{tabular}{|c|c|c|c|c|}
\hline \multirow{2}{*}{ Variables } & \multicolumn{2}{|c|}{ Gender } & \multirow{2}{*}{$\chi^{2}$} & \multirow{2}{*}{$\mathbf{P}$} \\
\hline & Boy & Girl & & \\
\hline Total & $87754(55.3)$ & $70830(44.7)$ & & \\
\hline High and low shoulder & & & 9709.54 & $<0.001$ \\
\hline Normal & $48849(55.7)$ & $22983(32.4)$ & & \\
\hline Left shoulder height & $24001(27.3)$ & $23934(33.8)$ & & \\
\hline Right shoulder height & $14904(17.0)$ & $23913(33.8)$ & & \\
\hline Scapula tilt & & & 4431.13 & $<0.001$ \\
\hline Normal & $56530(64.4)$ & $35165(49.7)$ & & \\
\hline Tilt to the left & $20592(23.5)$ & $19415(27.4)$ & & \\
\hline Tilt to the right & $10632(12.1)$ & $16250(22.9)$ & & \\
\hline Pelvic tilt & & & 2167.83 & $<0.001$ \\
\hline Normal & $71393(81.4)$ & $63251(89.3)$ & & \\
\hline Tilt to the left & $6182(7.0)$ & $3719(5.3)$ & & \\
\hline Tilt to the right & $10179(11.6)$ & $3860(5.4)$ & & \\
\hline Flat back & & & 263.56 & $<0.001$ \\
\hline Normal & $87422(99.6)$ & 70085 (98.9) & & \\
\hline Abnormal & $332(0.4)$ & $745(1.1)$ & & \\
\hline Kyphosis & & & 128.61 & $<0.001$ \\
\hline Normal & $84998(96.9)$ & $69266(97.8)$ & & \\
\hline Abnormal & $2756(3.1)$ & $1564(2.2)$ & & \\
\hline Lumbar concave & & & 2164.81 & $<0.001$ \\
\hline Normal & $71393(81.4)$ & $50773(71.7)$ & & \\
\hline Left concave & $6182(7.0)$ & $8572(12.1)$ & & \\
\hline Right concave & $10179(11.6)$ & $11485(16.2)$ & & \\
\hline Lumbar lordosis & & & 20.18 & $<0.001$ \\
\hline Normal & $87400(99.6)$ & $70434(99.4)$ & & \\
\hline
\end{tabular}




\begin{tabular}{|c|c|c|c|c|}
\hline Abnormal & $354(0.4)$ & $396(0.6)$ & & \\
\hline Lumbar kyphosis & & & 22.43 & $<0.001$ \\
\hline Normal & $87619(99.8)$ & 70645 (99.7) & & \\
\hline Abnormal & $135(0.2)$ & $185(0.3)$ & & \\
\hline Angle of thoracic rotation & & & 383.52 & $<0.001$ \\
\hline Normal (ATR: $0-5^{\circ}$ ) & $86886(99.0)$ & $69353(97.9)$ & & \\
\hline Rotate to the left $\left(\mathrm{ATR}>5^{\circ}\right)$ & $343(0.4)$ & $353(0.5)$ & & \\
\hline Rotate to the right $\left(\mathrm{ATR}>5^{\circ}\right)$ & $525(0.6)$ & $1124(1.6)$ & & \\
\hline Angle of lumbar rotation & & & 476.74 & $<0.001$ \\
\hline Normal (ATR: $0-5^{\circ}$ ) & $86548(98.6)$ & $68743(97.1)$ & & \\
\hline Rotate to the left $\left(\mathrm{ATR}>5^{\circ}\right)$ & $898(1.0)$ & $1572(2.2)$ & & \\
\hline Rotate to the right $\left(\mathrm{ATR}>5^{\circ}\right)$ & $308(0.4)$ & $515(0.7)$ & & \\
\hline Angle of thoracolumbar rotation & & & 92.53 & $<0.001$ \\
\hline Normal (ATR: $0-5^{\circ}$ ) & $87492(99.7)$ & $70393(99.3)$ & & \\
\hline Rotate to the left $\left(\mathrm{ATR}>5^{\circ}\right)$ & $125(0.1)$ & $184(0.3)$ & & \\
\hline Rotate to the right $\left(\mathrm{ATR}>5^{\circ}\right)$ & $137(0.2)$ & $253(0.4)$ & & \\
\hline Abnormal body posturea & & & 6519.15 & $<0.001$ \\
\hline Normal & $38071(43.4)$ & $16977(24.0)$ & & \\
\hline Abnormal & $49683(56.6)$ & $53853(76.0)$ & & \\
\hline Referral for radiographyb & & & 822.31 & $<0.001$ \\
\hline No & $85606(97.6)$ & $67169(94.8)$ & & \\
\hline Yes & $2148(2.4)$ & $3661(5.2)$ & & \\
\hline
\end{tabular}

Abbreviations: ATR: Angle of Trunk Rotation.

a) Abnormal body posture was defined as participant who was screened out one or more to the following abnormal physical signs: high and low shoulder, scapula tilt, pelvic tilt, flat back, kyphosis, lumbar concave, lumbar lordosis, lumbar kyphosis, angle of thoracic rotation $>5^{\circ}$, angle of lumbar rotation $>5^{\circ}$, angle of thoracolumbar rotation $>5^{\circ}$.

b) Referral for radiography: an angle of trunk (thoracic, lumbar or thoracolumbar) rotation of $5^{\circ}$ was the recommended threshold for referral to radiography.

Prevalence of Abnormal Body Posture of Chinese

\section{Children and Adolescents Stratified by Age}

According to age (as shown in Table 4), the prevalence of abnormal body posture was significantly higher in students aged $10-15$ and $>15$ years old than that in students $<10$ years old $(64.8 \%$ and $71.1 \%$ vs. $41.3 \%, \chi^{2}=681.18, \mathrm{P}<0.001$ ), students aged $10-15$ and $>15$ years old had a 1.57 and 1.72 times higher prevalence of abnormal body posture than students $<10$ years old, respectively. Students aged 10-15 and $>15$ years old had a higher prevalence of referral for radiography than students $<10$ years old $(3.3 \%$ and $6.7 \%$ vs. $0.5 \%, \chi^{2}=590.82, \mathrm{P}<0.001$ ). Besides lumbar lordosis and lumbar kyphosis, the rest of the abnormal signs were higher for students aged 10-15 and $>15$ years old than students $<10$ years old.

Table 4: Prevalence of abnormal body posture stratified by age $(\mathrm{N}=158,584)$.

\begin{tabular}{|c|c|c|c|c|c|}
\hline \multirow{2}{*}{ Variables } & \multicolumn{3}{|c|}{ Age (year) } & \multirow{2}{*}{$\chi^{2}$} & \multirow{2}{*}{$\mathbf{P}$} \\
\hline & $<10$ & $10-15$ & $>15$ & & \\
\hline Total & $1510(0.9)$ & $138279(87.2)$ & $18795(11.9)$ & & \\
\hline High and low shoulder & & & & 798.23 & $<0.001$ \\
\hline Normal & $1050(69.5)$ & $63376(45.8)$ & $7406(39.4)$ & & \\
\hline Left shoulder height & $158(10.5)$ & $40965(29.6)$ & $6812(36.2)$ & & \\
\hline Right shoulder height & $302(20.0)$ & $33938(24.6)$ & $4577(24.4)$ & & \\
\hline Scapula tilt & & & & 203.03 & $<0.001$ \\
\hline Normal & 1107 (73.3) & $80096(57.9)$ & $10492(55.8)$ & & \\
\hline Tilt to the left & $197(13.1)$ & 34707 (25.1) & $5103(27.2)$ & & \\
\hline
\end{tabular}




\begin{tabular}{|c|c|c|c|c|c|}
\hline Tilt to the right & $206(13.6)$ & $23476(17.0)$ & $3200(17.0)$ & & \\
\hline Pelvic tilt & & & & 101.97 & $<0.001$ \\
\hline Normal & $1492(98.8)$ & $127453(92.2)$ & $17220(91.6)$ & & \\
\hline Tilt to the left & $7(0.5)$ & $5264(3.8)$ & $738(3.9)$ & & \\
\hline Tilt to the right & $11(0.7)$ & $5562(4.0)$ & $837(4.5)$ & & \\
\hline Flat back & & & & 94.57 & $<0.001$ \\
\hline Normal & $1506(99.7)$ & $137435(99.4)$ & $18566(98.8)$ & & \\
\hline Abnormal & $4(0.3)$ & $844(0.6)$ & $229(1.2)$ & & \\
\hline Kyphosis & & & & 34.76 & $<0.001$ \\
\hline Normal & $1498(99.2)$ & $134410(97.2)$ & $18356(97.7)$ & & \\
\hline Abnormal & $12(0.8)$ & $3869(2.8)$ & $439(2.3)$ & & \\
\hline Lumbar concave & & & & 432.13 & $<0.001$ \\
\hline Normal & $1365(90.4)$ & $107214(77.5)$ & $13587(72.3)$ & & \\
\hline Left concave & $62(4.1)$ & $12444(9.0)$ & $2248(12.0)$ & & \\
\hline Right concave & $83(5.5)$ & $18621(13.5)$ & $2960(15.7)$ & & \\
\hline Lumbar lordosis & & & & 4.06 & 0.132 \\
\hline Normal & 1501 (99.4) & $137610(99.5)$ & $18723(99.6)$ & & \\
\hline Abnormal & $9(0.6)$ & $669(0.5)$ & $72(0.4)$ & & \\
\hline Lumbar kyphosis & & & & 1.39 & 0.499 \\
\hline Normal & $1509(99.9)$ & $137998(99.8)$ & 18757 (99.8) & & \\
\hline Abnormal & $1(0.1)$ & $281(0.2)$ & $38(0.2)$ & & \\
\hline Angle of thoracic rotation & & & & & $<0.001 c$ \\
\hline Normal (ATR: $0-5^{\circ}$ ) & 1509 (99.9) & 136425 (98.7) & $18305(97.4)$ & & \\
\hline Rotate to the left $\left(\mathrm{ATR}>5^{\circ}\right)$ & $0(0.0)$ & $571(0.4)$ & $125(0.7)$ & & \\
\hline Rotate to the right $\left(\mathrm{ATR}>5^{\circ}\right)$ & $1(0.1)$ & $1283(0.9)$ & $365(1.9)$ & & \\
\hline Angle of lumbar rotation & & & & 380.50 & $<0.001$ \\
\hline Normal (ATR: $0-5^{\circ}$ ) & 1505 (99.7) & $135729(98.2)$ & 18057 (96.1) & & \\
\hline Rotate to the left $\left(\mathrm{ATR}>5^{\circ}\right)$ & $3(0.2)$ & $1896(1.4)$ & $571(3.0)$ & & \\
\hline Rotate to the right $\left(\mathrm{ATR}>5^{\circ}\right)$ & $2(0.1)$ & $654(0.4)$ & $167(0.9)$ & & \\
\hline Angle of thoracolumbar rotation & & & & & $<0.001 \mathrm{c}$ \\
\hline Normal (ATR: $0-5^{\circ}$ ) & $1508(99.9)$ & 137741 (99.6) & $18636(99.2)$ & & \\
\hline Rotate to the left $\left(\mathrm{ATR}>5^{\circ}\right)$ & $0(0.0)$ & $234(0.2)$ & $75(0.4)$ & & \\
\hline Rotate to the right $\left(\mathrm{ATR}>5^{\circ}\right)$ & $2(0.1)$ & $304(0.2)$ & $84(0.4)$ & & \\
\hline Abnormal body posture ${ }^{a}$ & & & & 681.18 & $<0.001$ \\
\hline Normal & $887(58.7)$ & $48728(35.2)$ & $5433(28.9)$ & & \\
\hline Abnormal & $623(41.3)$ & $89551(64.8)$ & $13362(71.1)$ & & \\
\hline Referral for radiography ${ }^{b}$ & & & & 590.82 & $<0.001$ \\
\hline No & $1502(99.5)$ & $133738(96.7)$ & $17535(93.3)$ & & \\
\hline Yes & $8(0.5)$ & $4541(3.3)$ & $1260(6.7)$ & & \\
\hline
\end{tabular}

Abbreviations: ATR: Angle of Trunk Rotation.

a) Abnormal body posture was defined as participant who was screened out one or more to the following abnormal physical signs: high and low shoulder, scapula tilt, pelvic tilt, flat back, kyphosis, lumbar concave, lumbar lordosis, lumbar kyphosis, angle of thoracic rotation $>5^{\circ}$, angle of lumbar rotation $>5^{\circ}$, angle of thoracolumbar rotation $>5^{\circ}$.

b) Referral for radiography: an angle of trunk (thoracic, lumbar or thoracolumbar) rotation of $5^{\circ}$ was the recommended threshold for referral to radiography.

c) Fisher's exact probability test. 


\section{Discussion}

In this study, our large-scale cross-sectional study found that Chinese children and adolescents had serious body posture problems, around $3.7 \%$ children and adolescents were referred for radiography, girls and senior students were especially at high risk. These findings help describe the epidemiological characteristics of abnormal body posture in Chinese children and adolescents and provide evidence for identifying high-risk groups. Our results illustrated that the overall prevalence of abnormal body posture among children and adolescents in China was 65.3\%, around 3.7\% of children and adolescents were referred for radiography, which was similar to previous research findings $[15,18]$. In western countries, most of the primary and secondary school students have a certain degree of abnormal body posture, only 18\%-50\% of children and adolescents have a normal body posture $[19,20]$. The findings of our study in the coastal areas of South China also showed the similar epidemic characteristics with the previous studies, the high and low shoulders and scapula tilt account for a high proportion, indicating that the physical posture of children and adolescents in China has become more serious, which needs to be highly concerned by education departments and related public health organizations.

Furthermore, our group comparison results showed that the prevalence of abnormal body posture in girls was much higher than that in boys, 5.2\% girls were referred for radiography which was 2.2 times higher than that in boys. Our findings were consistent with Alen [21] and Penha et al. [22], but a study conducted in northern China showed that boys had a higher prevalence of abnormal body posture than that of girls [23]. This variation in results may derive from the different sampling areas and age structures. Due to the earlier physiological development, girls are more likely to extend their neck and chest to reduce the change of appearance image $[24,25]$. Besides, girls are less than boys in physical activity intensity, which tends to lead to lack of muscle strength, resulting in girls are more difficult to control body posture than boys [26]. Therefore, based on these possible reasons, girls may be a highrisk group with abnormal body posture. Previous studies have shown that with age, children and adolescents' body posture problems would become more serious [27]. Our results also found that students aged 10-15 and >15 years old had more serious body posture problems than the students aged $<10$ years old. The reason for the rising trend of abnormal body posture rate with the aging may be related to the increase of hormone secretion and the significant changes of physical development and mental status in adolescence [28,29]. Therefore, adolescence may be a period of high incidence of abnormal body posture. In our large-scale school screening program conducted in south China, apart from the objective criteria (ATR of thoracic, lumbar, or thoracolumbar), a student would also be examined when there were significant signs of body appearances, including uneven shoulder height, scapular prominence, hip and pelvic obliquity, and so son [13,15]. According to our best knowledge, this is the first population-based, crosssectional study to report the prevalence of abnormal body posture of children and adolescents. Our findings can provide essential information to the understanding of the epidemiology of abnormal body posture, which can be an important reason for progression to adolescent idiopathic scoliosis, and to help policymakers develop appropriate program through rational planning.

Our data showed that there is a high prevalence of abnormal body posture among Chinese children and adolescents, it is of importance to screen boys and senior students for a significantly high rate. The present study has several limitations that are worth noting. First, due to the cross-sectional nature of the data, it is difficult to make causal inferences. Second, our study sample included only school students and did not include children and adolescents who had dropped out of school or were not present in school on the day the screening was conducted. Third, although gender and age have been reported to be important factors in abnormal body posture [27] other relevant influencing factors (e.g., genetics, hormone, and nutritional status) [30-32] have not been investigated in this study.

\section{Conclusion}

Our large-scale epidemiology evidence showed that Chinese children and adolescents have a significantly higher prevalence of abnormal body posture, girls and older students may be an especially high-risk group. Appropriate prevention and intervention programs targeting for school students should be established to improve their physical health.

\section{Acknowledgment}

The authors would like to express sincere respect to the local health professionals and department of education, and to thank Director Ling Zhang for their valuable contribution in setting up the Shenzhen school screening program. In addition, the authors also thank Mr. Qihua Que, Ms. Qian Zhang, and other rehabilitation therapists for screening tests of school students and data collection. Finally, we would like to thank Ms. Qiaohong Chen for providing professional language help.

\section{Author Contributions}

Conceptualization, Yeen Huang, Bin Yan, and Lei Yang; Data curation, Xinhai Lu; Formal analysis, Yeen Huang and Bin Yan; Investigation, Lei Yang and Xinhai Lu; Supervision, Yeen Huang and Bin Yan; Writing-original draft, Lei Yang and Yeen Huang; Writingreview \& editing, Yeen Huang and Bin Yan.

\section{Funding}

This work was supported by the Scoliosis screening program for primary and secondary school students in Shenzhen (Project number: SFG [2019] No.780). 


\section{References}

1. Dolphens M, Cagnie B, Coorevits P, Vanderstraeten G, Cardon G, et al (2012) Sagittal standing posture and its association with spinal pain: A school-based epidemiological study of 1196 Flemish adolescents before age at peak height velocity. Spine 37(19): 1657-1666.

2. Louw QA, Morris LD, Grimmer-Somers K (2007) The Prevalence of low back pain in Africa: a systematic review. BMC Musculoskelet Disord 8: 105.

3. Nissinen M, Heliövaara M, Seitsamo J, Poussa M (1993) Trunk asymmetry, posture, growth and risk of scoliosis. A three-year follow-up of Finnish prepubertal school children. Spine 18(1): 8-13.

4. Nault ML, Allard P, Hinse S, Le Blanc R, Caron O, et al. (2002) Relations between standing stability and body posture parameters in adolescent idiopathic scoliosis. Spine 27(17): 1911-1917.

5. Motylewski S, Zientala A, Pawlicka Lisowska A, Poziomska Piątkowska E (2016) Assessment of body posture in 12- and 13-year-olds attending primary schools in Pabianice. Pol Merkur Lekarski 39(234): 368-371.

6. Mahlknecht JF (2007) The prevalence of postural disorders in children and adolescents: a cross sectional study. Z Orthop Unfall 145(3): 338342.

7. Kamal SA (2008) Pattern recognition using moiré fringe topography and rasrerstereography. Int sym bio sec tech 1-7.

8. Syazwan AI, Azhar MN, Anita AR, Azizan Hs, Shaharuddin Ms, et al (2011) Poor sitting posture and a heavy schoolbag as contributors to musculoskeletal pain in children: an ergonomic school education intervention program. J Pain Res 4: 287-296.

9. Kasten AP, Rosa BND, Schmit EFD, Noll Matias, Candotti CT (2017) Prevalence of postural deviations in the spine in schoolchildren: systematic review with meta-analysis. J Hum Grow Dev 27(1)

10. Xing Fei (2018) Investigation and analysis on the status quo of abnormal body posture of primary and secondary school students-Taking Beijing as an example. Gui spo sci tech 133: 54-57.

11. (2019) National Health and Family Planning Commission of the people's Republic of China and National Standardization Administration Commission of China. Screening of spinal curvature abnormality of children and adolescents.

12. Grossman DC, Curry SJ, Owens DK, Barry MJ, Davidson KW, et al. (2018) Screening for Adolescent Idiopathic Scoliosis: US Preventive Services Task Force Recommendation Statement. JAMA 319(2): 165-172.

13. Hengwei F, Zifang H, Qifei W, Weiqing T, Nali D, et al. (2016) Prevalence of Idiopathic Scoliosis in Chinese Schoolchildren: A Large, PopulationBased Study. Spine 41(3): 259-264.

14. Fong DY, Lee CF, Cheung KM, Cheng JC, Ng BK, et al. (2010) A metaanalysis of the clinical effectiveness of school scoliosis screening. Spine 35(10): 1061-1071.

15. Luk KD, Lee CF, Cheung KM, Cheng JC, Ng BK, et al. (2010) Clinica effectiveness of school screening for adolescent idiopathic scoliosis: A large population-based retrospective cohort study. Spine 35(17): 16071614.

ISSN: 2574-1241

DOI: $10.26717 /$ BJSTR.2020.25.004140

Yeen Huang. Biomed J Sci \& Tech Res

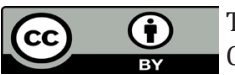

This work is licensed under Creative Commons Attribution 4.0 License

Submission Link: https://biomedres.us/submit-manuscript.php
16. Grossman TW, Mazur JM, Cummings RJ (1995) An evaluation of the Adams forward bend test and the scoliometer in a scoliosis school screening setting. J Pediatr Orthop 15(4): 535-538.

17. Yang Z, Wang K, Li T, Sun W, Li Y, et al. (1998) Childhood Diabetes in China: Enormous variation by place and ethnic group. Diabetes Care 21(4): 525-529.

18. Lee C, Fong DY, Cheung KM, Cheng JC, Ng BK, et al. (2010) Referral criteria for school scoliosis screening: assessment and recommendations based on a large longitudinally followed cohort. Spine 35(25): E1492-E1498.

19. Kratenová J, Zejglicová K, Malý M, Filipová V (2007) Prevalence and risk factors of poor posture in school children in the Czech Republic. J Sch Health 77(3): 131-137.

20. Jakub P, Pawel Posluszny, Jarosław Fugiel (2011) Prevalence of postural disorders in children from Copper Basin in Poland. Fizjoter 19(4): 3-10.

21. Alen ćirić, Denis Čaušević, Almir Bejdić (2015) Differences in posture status between boys and girls 6 to 9 years of age. Homo Sporticus 7(1): 15.

22. Penha PJ, Penha NLJ, De Carvalho BKG, Andrade RM, Schmitt ACB et al. (2017) Posture Alignment of Adolescent Idiopathic Scoliosis: Photogrammetry in Scoliosis School Screening. J Manipulative Physiol Ther 40(6): 441-451.

23. Li L (2018) The current situation of poor body shape of primary school students in Shijiazhuang. China school health 39: 1416-1418.

24. Pat Hartley (1993) Body images: Development, deviance, and change. Ann Plast Surg 1(1).

25. Feingold A, Mazzella R (1998) Gender differences in body image are increasing. Psy Sci 9(3): 190-195.

26. Klassonheggebo L, Anderssen SA (2003) Gender and age differences in relation to the recommendations of physical activity among Norwegian children and youth. Scand J Med Sci Sports 13(5): 293-298.

27. Ludwig O, Mazet C, Mazet D, Hammes A, Schmitt E (2016) Agedependency of posture parameters in children and adolescents. J Phys Ther Sci 28(5): 1607-1610.

28. Richmond E, Rogol AD (2016) Endocrine Responses to Exercise in the Developing Child and Adolescent. Front Horm Res 47: 58-67.

29. Hackney AC, Davis HC, Lane AR (2016) Growth Hormone-Insulin-Like Growth Factor Axis, Thyroid Axis, Prolactin, and Exercise. Front Horm Res 47: 1-11.

30. Weinstein SL, Dolan LA, Cheng JC, Danielsson A, Morcuende JA (2008) Adolescent idiopathic scoliosis. Lancet 371(9623): 1527-1537.

31. Yang Y, Wu Z, Zhao T, Wang H, Zhao D, et al. (2009) Adolescent Idiopathic Scoliosis and the Single-nucleotide Polymorphism of the Growth Hormone Receptor and IGF-1 Genes. Orthopedics 32(6): 411-416.

32. Sousa A, Fonseca I, Pichel F, Amaral TF (2016) Effects of Posture and Body Mass Index on Body Girth Assessment. Nutr Clin Pract 31(5): 690694.

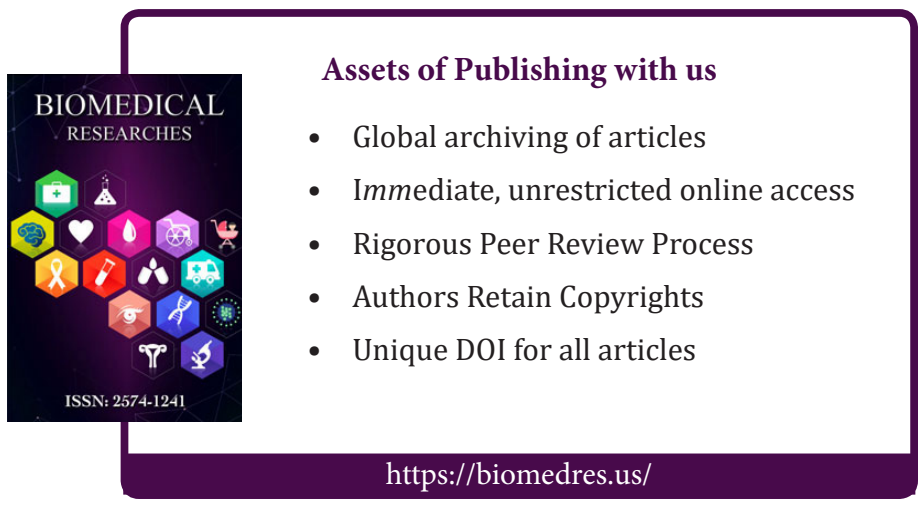

